\title{
The end of resident all-nighters?
}

$\mathrm{S}$ leepless 24-hour shifts for medical residents should come to an end, says a new report by the Royal College of Physicians and Surgeons of Canada and endorsed by representatives of the major professional and regulatory bodies representing Canada's doctors.

Working for 24 hours without sleep poses risks to the "physical, mental and occupational health of residents," states the report, Fatigue, Risk, \& Excellence: Towards a Pan-Canadian Consensus on Resident Duty Hours (www.residentdutyhours.ca/documents /fatigue_risk_and_excellence.pdf), released June 27 by the National Steering Committee on Resident Duty Hours.

The committee included representatives from the Association of Canadian Academic Healthcare Organizations, the Association of Faculties of Medicine of Canada, the Canadian Association of Internes and Residents, the Canadian Medical Association, the Collège des médecins du Québec, the College of Family Physicians of Canada, the Fédération des médecins résidents du Québec and the Federal, Provincial and Territorial Committee on Health Workforce.

Although the report says that 24hour shifts "should only be undertaken in rare and exceptional circumstances," it does not suggest a maximum shift length.

"We think that duty hours are part of a bigger problem of fatigue," says Dr. Kevin Imrie, coauthor of the report and vice-president of education for the Royal College of Physicians and Surgeons of Canada.

"It's an important contributor, but there are other things, like working at night and workload. We need a strategy that deals with all of those things. And we need solutions that are customized. We have residents working in large academic centres and smaller centres; on services where they do get regular sleep, on services where they don't. Coming up with a rigid number that

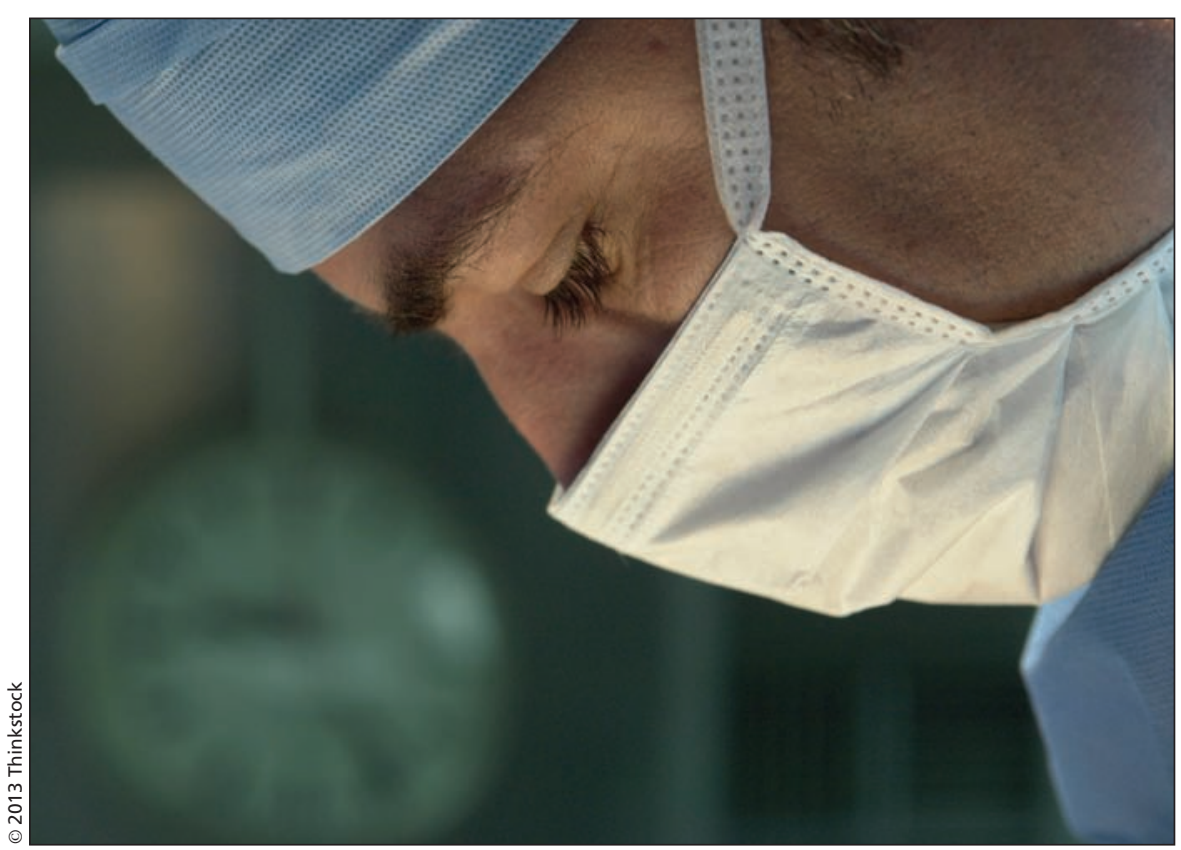

Working around the clock without sleep poses risks to the "physical, mental and occupational health of residents," states a new report.

would apply in all cases is not, we think, the right strategy."

Instead of a maximum duty period, the report recommends that residency education programs develop a "fatigue risk management plan." The plan could include rules around shift length, time off and transitions between night and day shifts. It could also include training on recognizing and mitigating the effects of fatigue, and effectively passing on patient information during shift turnover.

Imrie said that as a result of the report, Canada's three medical accreditation bodies - the Royal College of Physicians and Surgeons of Canada, the College of Family Physicians of Canada and the Collège des médecins Du Québec - may refuse to accredit residency training programs without effective fatigue risk management plans. "What we really like about this report is that it reframes the issue from pure residents' work hours to fatigue management," says Dr. Mathieu Dufour, former vice-president of the Canadian Association of Internes and Residents, who sat on the steering committee.
Dufour said that many hospitals are already moving away from 24-hour duty periods for residents. He believes this trend will continue as new collective agreements are negotiated following this report and the consensus that it represents.

Medical regulatory bodies have long wrestled with residents' duty hours, arguing on the one hand that 24-hourplus shifts can provide more learning opportunities, greater continuity of care for patients and mimic the real-life working conditions in certain specialties; but acknowledging on the other that these shifts may hurt residents' health and impair their concentration, potentially leading to errors that could harm patients.

The issue came to the fore in Canada in 2011, when a labour arbitrator upheld a grievance by the Association des Résidents de McGill over the requirement to work 24-hour shifts at the McGill University Health Centre in Montréal, Quebec. Citing the evidence of Harvard Medical School sleep specialist Dr. Charles Czeisler - that 
chronic sleep deprivation increases the risk of hypertension, diabetes, obesity, depression, cardiac problems and strokes - arbitrator Jean-Pierre Lussier ruled that 24-hour shifts violated the "security of the person" as guaranteed in the Canadian Charter of Rights and Freedoms (www.fmrq.qc.ca/PDF/2011 -06-07_GriefHorairesGarde_Decision deMeJPLussier_VF.pdf).

Following the ruling, the Fédération des médecins residents du Québec negotiated an agreement with the provincial government that capped residents' day shifts at 16 hours and night shifts at 12 hours. The cap came into effect June 1, 2012. "Overall, it's worked well in most situations," says Dr. Joseph Dahine, the federation's president. "But for certain programs, the transition has been more difficult."

For example, residents in surgery or anesthesiology sometimes have to leave in the middle of an operation because their shift has ended, he said. Dahine said the national committee was wise not to put a hard cap on duty hours until more evidence is gathered. "The experience in Quebec shows there is no such thing as a cookie-cutter answer." — Kate Jaimet, Ottawa, Ont.

CMAJ 2013. DOI:10.1503/cmaj.109-4545 